The Geneva Papers on Risk and Insurance, 20 (No. 76, July 1995) 348-373

\title{
Environment and Insurability Strengths in Insurance?*
}

\author{
by David Clement**
}

\section{Introduction}

In such a wide ranging topic covering so many issues pertinent to the insurance industry it is diffult to encompass this within a relatively short paper. However I will attempt to focus one's mind onto the real issues to be considered, not only by the insurance industry, but also by national Governments, who are of course the insurer of last resort'.

We have heard much recently of the effects, both actual and projected of the change in climate leading to changing patterns of temperature, ${ }^{1}$ and weather related aspects which could potentially have a serious effect on life as we know it - whether this be in human terms with changes in crops and food resources, or in physical terms seen in changes in weather related problems which is an area I will attempt to deal with today. Records in the United States show that over the past 100 years the sea level has risen by approximately $300 \mathrm{~mm}$ along their Atlantic coastline causing beaches to recede between 60 and 100 metres on average. Stephen Leatherman, Director of the University of Maryland's Laboratory for Coastal Research advises that the sea level is currently at its highest for some 5,000 years, and is rising at a rate 10 times as great as during previous periods of time. ${ }^{2}$ The tides are expected to rise by a further $120 \mathrm{~mm}$ during the next $20 / 25$ years leading to further erosion of the natural coastal protection. Travellers Insurance Corporation has projected that with only modest global warming of $0.9^{\circ} \mathrm{F}$ by the year 2010 , the hurricane season in the United States will extend by up to 20 days, increase by $33 \%$ the numbers of hurricanes hitting the coastline, and escalate financial losses (not necessarily insured) by about $30 \%$.

We are told that the climate is changing ${ }^{3}$ and there does appear to be good evidence that this is indeed the case. Whether this is an actual change bought about by man's activities on this planet, and which is potentially irreversible, or merely part of the usual pattern of

\footnotetext{
* Paper presented at the MORE 10-Seminar in Courbevoie, France, November 1994.

** Managing Director, Toplis and Harding, London.

${ }^{1}$ Impact of Changing Weather Patterns on Insurance. Chartered Insurance Institute, Society of Fellows, May, 1994.

2 Time: Burned by Warming, 14 March, 1994.

${ }^{3}$ The Potential Effects of Climate Change in the United Kingsdom, HMSO (Department of the Environment) First Report, January, 1991.
} 
weather change over the aeons we do not know for certain. Alarmist theories are raised as to the future, but with no disrespect to those putting forward such views, in the insurance industry world-wide we have to be realists. Whilst theorists may well look one hundred years or more ahead, the insurer is interested in the current problems and how they are likely to effect his business NOW - and indeed if they are likely to effect him, how does he protect himself against the potential losses he might incur?

Let us not therefore think that with our talk of environmental issues WE are going to save the planet. We are not. The planet will eventually get rid of us. We must therefore look to our own relative short term survival in a profitable climate.

\section{The problem}

What is the problem? Statistical information is easy to come by in generalised format but difficult to obtain on specifics as insurers generally are very secretive when it comes to internal breakdowns of information relating to claims matters. Certainly the overall loss details are available - but not the specifics. I attempted to obtain information from the Association of British Insurers and was advised that they had tried to get the same information as that which I was seeking some three/four years ago, but could not get it. This is a serious drawback of the industry since it is only by co-operating in a positive manner that anything could be achieved which would ultimately mitigate the potential hazard to all. One is not looking to advise on premium levels and scope of cover, as that should always be left to the individual underwriter to assess to the good or otherwise of the insurer, but co-operation on an industry-wide basis, and on a global level to control the manner in which claims can arise and the results of these losses, has to be sensible for all in the insurance industry, both direct insurer and reinsurer.

Whilst society often looks upon payments by insurers as not effecting "them", it must be recognised that financial compensation is a drain upon the resources of that society as a whole. If buildings etc., are destroyed, then whilst monies from insurers may provide recompense to the owners and occupiers, those monies are taken from the "fund" of overall monies available to society and, having been expended, are no longer available to be utilised in other more useful ways that could in turn "generate" wealth.

Whilst the specific statistics are difficult to come by, there can be no doubt but that environmental issues and the insurance problems they pose, such as windstorm, flood, clay shrinkage, earthquake etc., in the aggregate cost more in claims payments than do non-environmental issues such as fire, theft etc. Other environmental issues, particularly pollution, also impinge substantially on claims costs - particularly when one considers liability aspects.

Pollution problems, which are very often associated with environmental and climatic issues are very well recognised, and legislation around the world has been enacted which in the majority of cases leads to these risks being generally well-controlled. All industries and indeed commercial development, whether this be subsistence farming to food production, metal processing, paint and chemicals, tanneries, textiles or the better recognised petro-chemical industry have their known risks. These are well-regulated within developed economies and are generally better regulated in the under-developed economies principally because many of the companies operating in those sector have international experience and exposure. The volumes written around the world on risk evaluation and management in these 
regards are legion, an example being The Loss Prevention Council report on Pollutant Industries of $1991 .{ }^{4}$ Whilst pollution is very much a major side-issue to the points discussed in this paper, I shall be concentrating more specifically upon the risks of flood, windstorm and associated perils.

Clearly the easiest way for insurers to protect themselves is to merely cease underwriting the risk, or to price their product in such a way that hardy anyone will purchase the cover, in which case it is hoped that the premiums achieved from the lessernumber of persons seeking the cover will meet the costs of the risk in the event that the peril befalls. Both these methods are negative in thinking and fail to achieve what is a fundamental requirement of the industry - to provide the cover needed by the consumer at a sensible cost, whilst at the same time achieving a profitable result for the insurer. What we must examine is a sensible way of achieving this. In the ultimate analysis if insurers walk away from the potential risks to the extent that insured losses rarely, if ever, occur -why do we need insurance at all?

We see an excellent example of this negative thinking in the way in which, for example, premiums have been structured in the West Indies. Whilst it is very understandable that reinsurers require to properly protect themselves, because no true global consensus can be achieved between both financial interests and government, the result is a very substantial escalation in premium base rates charged to the cedent insurers and a restriction of the basis of cover. This in turn results in the local insurer being required to increase their premiums to a level where insurance becomes a diminishing marginal utility, and because of this insurance purchased against windstorm, and interestingly earthquake also, is now considerably reduced.

Whilst clearly a joint approach between the insurer and the insuring public is to be recommended, higher deductibles, higher premiums, and more restrictive approaches do not necessarily lead to a long term benefit to Society as a whole. One needs to be pro-active in persuading consumers to take the necessary precautions to minimise the effects of natural disaster, the overall costs of which can only increase given escalating population and resources. World population has doubled from the 3 billions it was in 1960 but disaster losses both insured and un-insured - have risen almost ten-fold during the same period. 5

In the Pacific region as a result of Cyclones Ofa and Val in 1991/92, the Travellers Insurance Company merely withdrew further cover, whilst the local company, National Pacific initially withdrew cover, and then invited their clients to re-apply provided they could obtain an engineers' certificate that the properties had been rendered "cyclone-proof". ${ }^{6}$ This latter method shows a more compassionate attitude of the insurer and indicates a way forward.

Whilst from the insurers point of view their exposure is clearly much limited by this means, in the event of a further disaster striking the locality we must ask the question: How will we in the financial services sector be judged when a principal of insurance is to share the risk and to provide adequate cover at prices people can afford commensurate with the risk. Whilst insurers are NOT charitable organisations as such, unless they get their collec-

${ }^{4}$ Pollutant Industries: Safety, Health and Environment Review, The Loss Prevention Council, LRV911, June 1991.

5 Stop Disasters, The United Nations IDNDR Newsletter No. 15, Sept/Oct. 1993, p. 3.

${ }^{6}$ National Business Review, New Zealand, 1st, May, 1992. 
tive houses in order, they lay themselves open to substantial state interference. In the event of insurers failing to supply the products required, subsequent Government interference may well lead to an extension of consumerist protection and regulation over and above the very considerable levels of protection already seen in the United States, United Kingdom and Europe which many in the insurance industry already regard as being unfair. Governments may not necessarily be representative of the people they govern, but where potential financial loss is concerned all governments are able to pass responsibility to others by merely enacting measures which by any stretch of the imagination will prove popular to their peoples, and distinctly unsavoury for the insurers. In the case of earthquake mentioned above the reason for the rejection of insurance by a substantial sector of the purchasing market was the methods by which co-insurance clauses were enacted, which whilst I for one did not think unreasonable, from the perspective of the consumer struck them as totally unfair.

The perils stemming from environmental issues are generally well-known, but the effects of these individually and the resultant effects may not always be as well understood, least of all by insurers. As an example, during severe windstorm in terms of the highest value, the loss following damage is not necessarily to the structures, but to the contents which left exposed to the heavy rainfall which accompanies such conditions are often severely damaged. During 1988, Hurricane Gilbert caused very substantial damage to the University of the West Indies complex at Mona, Kingston, Jamaica. The roofs of many of the buildings were totally removed and as a result the heavy rainfall resulted in incalculable losses to the content - valuable books, scientific equipment etc., the resultant effect of which was certainly not foreseen by the insurers concerned at that time, nor indeed by the insured whose assessments of the values at risk left much to be desired, whoever was responsible for decising upon these values.

Valuation is a paper on its own but we do have a real problem in seeking to properly EDUCATE not only the consumers, but also the providers in just what is the reality of Adequate Sums Insured.

The important area we must look to therefore is PROTECTION. Protection of the contents in turn means Protection of the structures and will also result in Protection of the inhabitants as well, and this Protection of the risk will in turn protect the insurers and lead to a reduction of financial "wastage" to society as a whole in the event of the disaster striking - as it undeniably and eventually, will.

If we are to protect against the environmental hazards this requires PLANNING. This latter is not the responsibility of the insurer as individually he is not really in any position to control anything no matter how prestigious his organisation - there will always be someone prepared to undercut and take an easy way out in the hope of making a quick profit praying all the while that the claims will not occur as if they do he could well be financially embarrassed - even to the extent of being forced out of business altogether - as has already been seen recently in a number of cases. The catastrophic underwriting of recent years by organisations who should have known better is well seen in the recent cataclysmic situation in certain underwriting syndicates at Lloyd's for example. That this MUST not be allowed to happen again is clearly seen, with the good name of the entire organisation being sullied as a result of a few figures considered leading lights in their days, but who for sheer crass incompetence might hardly be equalled. This is an example of where an organisation could and should have controlled themselves better at the time and where the current generation 
have the almost insoluble problems of the past to confront. It is always much harder to catch the horse rather than closing the door before the horse bolts and preventing the problem arising in the first place.

What is needed is EDUCATION. Education of the insured, education of the market generally and, most importantly, education of society as a whole, and that means the Governments. It is not good enough to merely try to educate one Government however. It is a world-wide problem and the task of education is equally as daunting.

So how does the insurance industry educate those who may possibly feel their economic planning is best and that they have no need of being told what to do by those whose business is elsewhere? The insurance industry, globally, wields tremendous muscle and whilst individually they have little real power to influence events, collectively they have power far beyond what might be thought. Modern national economies are totally inter-related on a world-wide basis and without the protection provided by insurance, commerce would find it difficult, but not impossible, to achieve the production and growth rates they wish to, and do achieve. Because of the power they wield, insurers do have the power to influence decisions as to future Planning, Protections and Resourcing on a multi-national basis.

The insurers best able to achieve this would be those who may be looked upon as multinationals. But who are they? Quite frankly I cannot think of any specifically true multinational insurer or reinsurer. In my view in order to be looked upon as a multi-national a company has to have an identity that is instantly recognisable anywhere in the world. With no disrespect to the leading insurers, can any of them say they are in the same position as say "Coca-Cola" or "MacDonalds"? Whilst this may seem naive the point to make is that if "MacDonalds" for instance made a "Statement" relating to environmental issues - everyone would at the least take note. If for example the U.A.P. or Munich Re. were to make an identical statement, whilst within the insurance profession all would take note, society as a whole could frankly "not give a damn".

For this reason in order to achieve any real improvement in what is really "Risk Management" on a grand scale, the global insurance industry needs to get its collective act together, and to work in unison, possibly through the auspices of the United Nations organisation, to bring to governmental notice a serious erosion in the degree of risks insurers are being asked to underwrite. Merely to decide to restrict underwriting or to uplift premiums to dissuade clients is defeatism. Nevertheless the insurer is not a charitable organisation. It is in business to make a profit and to do this it requires reasonable returns on the capital employed. One is therefore not arguing for cheap insurance but for better risks.

How do we achieve this? PLANNING has to be the watchword, but Planning is generally the ultimate responsibility of government policies where catastrophe losses are concerned. For this reason the Governments need to be persuaded that it is in their interests to ensure the risk improvement is achieved. However, initially it is important to identify precisely what the risk we are examining actually is.

The Ministry of Agriculture Fisheries \& Food in the United Kingdom, in conjunction with the National Rivers Authority and the Association of British Insurers has recently participated in a study commissioned from Sir William Halcrow \& Partners on Coastal Flood Risks in England and Wales and their initial report has recently been published. Whilst the study may require refinement it does serve to show the manner in which co-operation between those best suited to be able to consider all the implications can occur, hopefully to the ultimate benefit of society. However it is important to consider just how will this Study 
be used? If it merely prompts the underwriters to rush to their bomb-proof shelters and reject insurance in vulnerable areas, and indeed possibly also seek to abrogate the 1961 Market Agreement within the United Kingdom on covering against flood losses in areas of high risk - then the study will frankly have been a waste of time insofar as Society is concerned. The underwriter trembling in his shelter would not agree with these sentiments, but the proper course of action to result from the study and its successors is for the financial markets in association with government to decide upon what action is best for the community as a whole to protect against loss. This could well be in the form of funding for protections, where we must ask the question, Who should pay?

Should the insurance industry meet the cost by means of a levy? We already have the start of Insurance taxation on policies issued within the United Kingdom and it would be preferablc to see the monies levied put to good use rather than just disappear into the insatiable maws of the Treasury. Should there be compulsion inflicted against insurers to ensure they adequately cover the risks? If so, how do you ensure that insurers not necessarily domiciled within the United Kingdom also share in these potential financial exposures? Should alternatively the cost of protections be met from local levies and taxes, or from national taxation? In many areas protections will be hopelessly uneconomic, even where protection IS possible. Who pays the costs in such cases? Do we leave the properties unprotected but try to force insurers to underwrite what must be an unacceptable risk? Questions, questions, questions. But at the end of the day, it is the duty of Society to provide the answers, and to enable the correct answers to be provided, the insurance sector does need to urgently get its collective act together.

Insurers can not resolve the matter in isolation any longer as the GATT implications recognise and promote an internationalisation of the insurance industry. Whilst we may look critically at the current "problem" areas, we must not overlook the potential for future problems in rapidly developing markets where insurance is becoming more accepted in those societies. China is an obvious example where with the increasing level of industrial development and modernisation coupled with a relaxation of earlier attitudes there will be requirements for cover against the risk of loss from substantial environmental problems - windstorm, flood, earthquake, etc. in these areas just as we now have in the developed areas of Europe. Currently, we are told the expenditure on insurance in China in 1992 represented just $0.7 \%$ of the Gross National Product for non-life business, as against premiums representing between $7 \%$ and $11 \%$ of G.N.P. in Western Europe and Japan. ${ }^{7}$ To take this comparison further in 1992 premium incomes pcr capita in South Korea were US\$825, in the Philippines US\$19, India, US\$5 and China only US\$3.5. ${ }^{8}$ It is clear that in the areas of China and India there is a vast potential for insurance cover requirements which, as industrialisation proceeds will place added responsibilities upon insurers. We are already aware of the potential for massive natural disasters in these lands and insurers must be ready to provide the cover when this is required.

Within the UK the report commissioned on potential coastal flooding has been made available and whilst considering this recent rcport on Coastal Flood Risk, it is most

7 From figures produced by the Swiss Re, 1992.

${ }^{8}$ David Brewer, Chairman Sedgwick Insurance \& Risk Management Consultants (China) Ltd. from paper given October 17, The Developments in the PRC Insurance Industry. 
important to stress that the information is put into a proper context to avoid alarmist theories being propounded by or to members of the public, just as much as the, I hope, hypothetical "trembling" underwriter mentioned above.

It is most important to stress that losses following disasters by flood, windstorm, earthquake etc., can not be prevented. What we are seeking to achieve is a REDUCTION in the risk. We cannot prevent the incident happening. But we can minimise its effect on the subject matter at risk - and ipso facto effect a reduction in the financial wastage so arising.

If we take as an example the report on coastal flood risk, this will undoubtedly be of benefit in enabling the Authorities to discourage development in areas of high flood or erosion risk; to encourage the provision of defences in these areas where development has already taken place and where it is economically worthwhile to do so; and thirdly to be in a position to encourage the provision of warning systems in those areas where defences of themselves will not be sufficient to safeguard primarily life, but property also.

Decisions as to whether to protect or not to protect are an extremely emotive subject. We have the conservationist, anxious to protect natural flora and fauna who reacts, understandably, but perhaps totally negatively, when it comes to building flood defences across "their" marshes, for example, with no real thought of the lives of others living in the immediate hazard area. Clearly economics has to play its part, with the decisions as to whether to provide, to strengthen existing, or to opt for a policy of managed retreat, relying upon a detailed economic appraisal in a location.

Within the United Kingdom, the national taxpayer provides virtually all the funding for flood and coast defence works - despite the fact that the direct beneficiaries are those living in the hazard area. As a result the economic appraisal has to be considered from a national standpoint on which basis it must be shown that the benefits - in terms of the losses avoided - are at the least equal to the costs of the scheme using the Treasury discount rate of 6 per cent per annum. To what extent should the financial industry participate both in the evaluation of such schemes but also the cost?

But are we merely interested in those schemes that are shown to be sensible following a detailed study similar to that just undertaken? Should we not also look to the performance of those defences already in place? Clearly since the extensive flooding on the east coast of Britain in 1953 very substantial monies have been expended in providing sea and estuarine protections over a wide area. But how effective have they been? What is the amount of "losses" avoided by the construction?

The Ministry of Agriculture Fisheries and Food and the National Rivers Authority have embarked upon initiatives in two main areas; firstly, with national surveys of the state of the repairs of the existing defences (The NRS published a Sea Defence survey in $1992^{9}$ and MAFF and the Welsh Office undertook a coast protection survey during 1993); and secondly a post-project evaluation of individual defence schemes at five yearly intervals to assess their actual performance when compared with the designed performance. We have a situation where protections have often "evolved" such as at Towyn, in North Wales, where what was designed as merely a railway embankment had effectively become a sea defence for

\footnotetext{
9 NRA Sea Defence Survey, pages I to III, 1992.
} 
properties constructed behind this, and on land which was unsuitable to say the least. That disaster had not struck previously did not abrogate the inevitability of the problem with the unsuitability of the "defence" that was actually in place.

As a part of their initiatives the Ministry of Agriculture Fisheries \& Food published an excellent "Strategy" document ${ }^{10}$ in which one most important criteria was stressed. In ALL cases of planning to avoid loss, the safeguarding of lives must have the highest priority. This is clearly seen in the measures for building construction controls in the United States earthquake zones, where the object is to save life - not property. Here properties may well be damaged to the extent of becoming total losses, but because they do not generally collapse in upon themselves, when properly constructed, the loss of life is very much reduced. Whilst in the property and liability insurance sector this may appear of little real interest to them, the fact remains that where concentrations of people live and work are found the concentrations of industry, commerce and housing, and as a result the protections of lives are substantially inter-related to the protections of property - particularly in the case of flood and windstorm.

The Society of Fellows recently reported ${ }^{11}$ that it should be very exceptional for flood damage to property to be an "uninsurable risk". From the population's point of view this is a vital consideration when it is realised that some $52 \%$ of all agricultural land, including practically all Grade 1 land is dependent upon drainage and flood protection to maintain its productivity. ${ }^{12} \mathrm{~A}$ significant percentage of the population and industrial/commercial enterprise is similarly located in what might be termed "risk areas" and it is interesting to consider that whilst as an example the planned expenditure centrally for flood and coastal defence in 1993/94 was about $£ 300$ millions, this was only a fractional amount when compared to the value of the property protected. I would think that it is incumbent upon insurers to ensure that cover IS available in all such areas, as if cover for flood insurance was to be either withdrawn or alternatively priced out of the reach of the Average Consumer despite the scale of public investment in defences, government interference would certainly be greatly encouraged, and such interference would - given the current public view of insurance be not unpopular!

Indeed it could well be appropriate in certain instances, particularly windstorm, for insurers to consider the possibility of coinsurance arrangements entered into with governments. This would be particularly pertinent in some of the high risk Caribbean countries and in the Pacific.

We have looked for some while at flood-related matters but windstorm has to be one of the most serious potential risks to insurance in many of the developed and developing economies. As an example in the United States, Aetna Life \& Casualty announced in March 1994 , that first quarter earnings would plunge $\$ 120$ millions - due to claims from January and February 1994 weather. Within the United States insurance market, weather related claims for those two months of extreme cold and heavy snows added some $\$ 825$ millions,

10 Strategy for Flood and Coastal Defence in England \& Wales, Ministry of Agriculture Fisheries and Food, September 1993.

11 The Impact of Changing Weather Patterns on Property Insurance, Chartered Insurance Institute, Society of Fellows Study Group, May 1994.

12 Strategy for Flood \& Coastal Defence in England \& Wales, p. 7 . 
which was on top of the $\$ 1.75$ billions caused by the winter storms that battered 24 American states in March 1993, and the $\$ 19.5$ billions in insured losses resulting from Hurricane Andrew, which actually missed New Orleans and Miami. Had it hit these cities the resultant losses would have been even more catastrophic. ${ }^{13}$ Storms, flood and droughts hit populated areas with greater frequency and with greater severity than had been predicted with natural disasters during the 1980 's being $94 \%$ more frequent than in the 1970 's. ${ }^{14}$

The importance of these statistics can be appreciated when we remember that Cyclone Iniki destroyed property to the value of $30 \%$ of the Sums Insured on Hawaii alone, ${ }^{15}$ whilst Hurricane Gilbert in Jamaica in 1988 although considered more serious, resulted in a loss equivalent to $8 \%$ of the overall Sums Insured. ${ }^{16}$

This rapidly escalating phenomena can be seen in financial terms:

Major windstorms world-wide annual impact 1960-1992

\begin{tabular}{lccccc}
\hline & 1960 's & 1970 's & 1980 's & $1990-92$ & Factor 1980's/60's \\
\hline Number & 8 & 13 & 29 & 5.0 & 3.6 \\
Total damage (\$bns) & 2.0 & 2.9 & 3.4 & 20.2 & 1.7 \\
Insured cost (\$bns) & 0.5 & 0.8 & 1.7 & 11.3 & 3.5 \\
\\
Notes: 1. Valued at 1990 prices \\
$\quad \begin{array}{l}\text { 2. Figures above are for Major windstorms only. Normal losses arising from smaller storms are } \\
\quad \text { not included. }\end{array}$ \\
$\quad$ 3. A major windstorm is defined as one costing more than \$500 millions in total damage. ${ }^{17}$ \\
\hline
\end{tabular}

Looking at individual natural disasters which cost the insurance industry more than $\$ 1$ billion shows that prior to 1987 only Hurricane Alicia in 1983 was recorded. From 1987 to 1989 there were two: one in North-western Europe in October 1987 costing $\$ 2.5$ billions; and Hurricane Hugo in the United States and Caribbean costing $\$ 5.8$ billions. There have been no less than 13 incidents during the period 1990-1993 as detailed below:

$\begin{array}{llll}\text { January } 1990 & \text { Northwest Europe } & \text { Windstorm "Daria" } & \$ 2.5 \text { billions } \\ \text { January } 1990 & \text { Northwest Europe } & \text { Windstorm "Herta" } & \$ 1.3 \text { billions } \\ \text { February 1990 } & \text { Northwest Europe } & \text { Windstorm "Vivian" } & \$ 3.2 \text { billions } \\ \text { February } 1990 & \text { Northwest Europe } & \text { Windstorm "Wibke" } & \$ 1.3 \text { billions } \\ \text { February } 1990 & \text { Samoa/Pacific } & \text { Cyclone "Ofa" } & \text { not recorded } \\ \text { July } 1990 & \text { United States } & \text { Colorado Storms } & \$ 1.0 \text { billion } \\ \text { September } 1991 & \text { Japan } & \text { Typhoon Mirielle } & \$ 4.8 \text { billions } \\ \text { December } 1991 & \text { Samoa/Pacific } & \text { Cyclon "Val" } & \text { not recorded }\end{array}$

13 per Dr. Gerhard Berz, Munich Re.

14 Time: Burned by Warming, March 14, 1994.

15 Colin Murray, Catastrophe Reinsurance Crisis in the Caribbean.

16 D. B. Clement, Life after Gilbert, An Analysis of Disaster, 1990, ISER, University of the West Indies, Jamaica.

17 Table from Impact of Changing Weather Patterns, p. 77, Data from Munich Re and Swiss Re. 


\begin{tabular}{|c|c|}
\hline August 1992 & United States \\
\hline August 1992 & Guam \\
\hline August 1992 & United States \\
\hline December 1992 & United States \\
\hline
\end{tabular}

That action must be taken cannot be doubted. Hurricane Andrew resulted in at least nine insurers being put out of business ${ }^{19}$ and even in September 1992 four of the top seventeen British composite insurers were trading below their correct solvency margins as a result of the 1990 storms. ${ }^{20}$ It is important to appreciate however that these rounded figures relate to insured losses only. The overall loss to the economy of a country is substantially greater when taking into account those uninsured aspects, disruption etc., which pushes the actual economic loss in most cases to approximately double the insured figure. Taking just the United Kingdom and the effects of the series of eight windstorms in January/March 1990 (some of which had an insured cost in excess of $\$ 1.0$ billion) the overall economic loss to the country was in the order of $\$ 20$ billions. ${ }^{21}$ Economic losses from windstorm have been increasing by a factor of 3 during the period 1960-1990, and insured losses by a factor of 5 over the same period, indicating the increasing use of insurance to protect property. ${ }^{22}$ These are actual figures and not the sometimes alarmist theories of individuals who, whilst they may believe passionately in the potential of holes in the ozone-layer, global warming and environmental pollution leading rapidly to the total demise of life as we know it - are merely propounding theories - which may or probably may not, come true. We must not let ourselves be led into realms of science fiction horror stories, but must weigh up carefully the evidence that we can actually see. We are told that the industrial gases sending chlorine into the atmosphere are responsible for the depletion of the ozone layer. This may or may not be true, but it is a fact that the total volume of chlorine released into the atmosphere by man is 7,500 tonnes per annum. But compare this to the 600 million tonnes from the evaporation of sea water and 36 million tons from from volcanic activity! Add to this that man's chlorine is produced generally in industrial areas of the globe, whilst the ozone breakdown appears to occur in the polar regions. Chlorine breaks down the atmosphere producing ozone, but ultra-violet rays turn the ozone back into oxygen. What does this prove? It shows that we do not know.

What is beyond argument however is that the wind damage turned out to be far greater in Hurricane Andrew - and in 1989's Hurricane Hugo - than many experts anticipated. Flooding, whiclı commercial insurers generally do not pay for in the United States, has been rightly regarded as the worst threat. Wind is unforgiving, at sufficiently high velocities; it mows down structures regardless of location and leaves total losses in its wake. Flooding, whilst no less capable of causing catastrophic damage, is confined to low lying areas and when the waters recede there may be salvageable structures still standing. ${ }^{23}$

\footnotetext{
18 Climate Change and the Insurance Industry, Greenpeace, Dr. Jeremy Leggett, p. 16.

19 Lloyd's List, 18th, January 1993.

20 Guardian, 3rd September 1992.

21 Winter Storms, 1990, Annual Report of the Swiss Re, 1990.

22 Windstorm, Munich Re, 1990.

23 Jack Weber, Executive Director, Natural Disaster Coalition, U.S.A.
} 
Many computer models used for research do not anticipate winds of $170 \mathrm{mph}$., or gusts of in excess of $200 \mathrm{mph}$., but Hurricane Gilbert reached a low barometric pressure of $888 \mathrm{mb}$., which until the passage of Hurricane Hugo in September 1989 was the lowest barometric pressure ever recorded in the Western Hemisphere ${ }^{24}$ and on that occasion the wind funnelling effect through the Mona Valley, north of Kingston, Jamaica resulted in wind speeds in the order of $200 \mathrm{mph}$. in a localised area which caused such exceptional damage to the University of the West Indies. ${ }^{25}$ Clearly therefore one must cater for velocities considered only recently to be beyond possibility.

The Swiss RE suggested in 1990 that the way forward was to:

a. Adjust insurance premiums

b. Increase insurance deductibles

c. Redistribute relative risk-sharing between insurers and reinsurers and promote coinsurance participation in reinsurance.

d. Change the cover provided under the policies (presumably by limiting this). ${ }^{26}$

Whilst these may well have been sensible suggestions, they did not fully address the problem. Prevention is better than the cure and the method adopted by the National Pacific Insurance after the Samoan cyclones ${ }^{27}$ was far more realistic insofar as their clients were concerned: If you did not ensure your property was protected and certified as such, then you could get no cover against windstorm.

There are many means of establishing the anticipated claims costs and examining risk exposures against the overall business portfolio; and underwriting methods designed to assess the peril rates from technical analysis of the peril hazard and the damage effect when compared with the return period and ratio of anticipated damage. The production of loss frequency curves by comparing event loss on a financial basis taking values per zone and the accumulation of aggregate retention's, with the peril rate. Jeremy Hindle of the Swiss Re. has given a detailed technical paper on this topic. But these areas of analysis are all subjective in that they deal with what is perceived to be the actuality; they do not concentrate upon steps which should be implemented to effect a reduction in the peril hazard and the damage effect. It is on this latter aspect insurers and society generally need to concentrate.

In 1992 Professor Robert L. Carter pointed out the necessity of non-life insurers being in a position to avoid uncertainty regarding claims costs as far as possible and the associated solvency problems that could arise. He went on to discuss the contribution of the insurance industry to the United Kingdom economy and in a global environment, and argued powerfully for better recognition by government. ${ }^{28}$

Whilst he was looking primarily at the taxation regime, the argument for co-operation between the sectors was overwhelming; and this argument transcends national boundaries. Insurance is a Global inter-related industry and must be seen as such.

${ }^{24}$ L. A. Eyre, Hurricane Gilbert, WEATHER, (April), vol. 44, No. 4, pp. 160-4.

${ }_{25}$ D. B. Clement, Life after Gilbert - An Analysis of Disaster, 1990, ISER, University of West Indies, Jamaica.

${ }^{26}$ Swiss Re, Annual Report, 1990.

27 National Business Review, New Zealand, 1st May 1992.

28 An Economic Study of the UK Non-life Insurance Industry and its main European Competitors - A Case for Action by the Government, Prof. Robert L. Carter, Association of British Insurers, August 1992. 
For this reason even the co-operation between the United Kingdom government and the British insurance market is still inadequate. The Global insurance industry does require a Global representation - and this forum for discussion and exchange of views is just not in place at the moment. The fact that there may be "Chief Executives" clubs on an international scale etc., is no substitute for a forum where practical persons can discuss, agree and thereafter ensure the enforcement of properly structured measures which both provide the. cover that is required to the consumers around the world, whilst at the same time affording governments some financial protections against disaster, and earning the insurance industry a sensible return on the monies invested and the risks they are taking.

This paper has dealt at some length with major catastrophes - windstorm, flooding etc., but I feel it is important to confirm that it is NOT just the disasters we are seeking to mitigate. It is the more usual every-day occurrence of windstorm, flood etc., which in its own way will cause substantial financial loss to the insurers, and which, because of the generally lower velocity in wind speed, is so much easier to mitigate against. Sigma/Swiss Re prepared a report ${ }^{29}$ showing that natural disasters and major losses in property insurance reached an unprecedented level of US $\$ 27.1$ billions in 1992 - an increase of $87 \%$ over the previous year, even after adjustment for inflation. Of this man-made losses accounted for a mere US\$4.6 billions. Natural disaster was therefore responsible for in excess of $83 \%$ of insured losses. The frequency and the adjusted value of such losses has shown a relentless and steady escalation in values over the 22 year period since 1970 , with the figure increasing from US\$10 billions in 1992. A table published by Swiss Re showing the number of occurrences and the loss size amounts shows the following:

\begin{tabular}{|c|c|c|c|}
\hline NUMBER OF OCCURRENCES PER YEAR. & $1970-81$ & $1982-92$ & CHANGE \\
\hline Losses below $\$ 100$ millions & 124.3 & 208.9 & +84.6 \\
\hline Losses $\$ 100 / \$ 1,000$ millions & 7.2 & 16.0 & +8.8 \\
\hline Losses greater then $\$ 1,000$ millions & 0.5 & 1.1 & +0.6 \\
\hline TOTAL & 132.0 & 226.0 & +94.0 \\
\hline \multicolumn{4}{|l|}{ LOSS VALUE PER YEAR: } \\
\hline Losses below $\$ 100$ millions & 1.6 & 2.1 & +0.5 \\
\hline Losses $\$ 100 / \$ 1,000$ millions & 1.6 & 3.7 & +2.1 \\
\hline Losses greater than $\$ 1,000$ millions & 0.6 & 3.8 & +3.2 \\
\hline TOTAL & 3.8 & 9.6 & +5.8 \\
\hline
\end{tabular}

${ }^{29}$ Natural Catastrophes and Major losses in 1992: Insured damage reaches a new record level, Swiss Re, Zurich, 1993. 
Swiss Re went on to identify the major incidents of 1992 in the following categories:

Natural disaster

Floods

Storms

58

Earthquake 13

Major fires

Industry

Buildings

Miscellaneous

Hotels

Oil/gas installations

Aviation

Crash

Damage on ground

Collision in the air

Space losses

Marine

Freighters

Passenger ships

Tankers

Ship collision $\quad 7$

Road/Rail

Buses/lorry

Railways

Collisions

Mining disasters

Collapse of bridges/buildings

Misellaneous

14

4

13

1

5

$37 \quad 11.5 \%$

15

3

2

$130 \quad 40.1 \%$

$29 \quad 9.0 \%$

30

\begin{tabular}{rc}
53 & $16.4 \%$ \\
7 & $2.2 \%$ \\
7 & $2.2 \%$ \\
30 & $9.3 \%$ \\
\hline 323 & $100.0 \%^{30}$ \\
\hline
\end{tabular}

Whilst one accepts that inflation has had an obvious effect upon the overall increase in the financial level of losses, there is no doubt but that the figures have outstripped the anticipated losses arising from inflationary factors alone. From this table it can be seen that whilst Natural Hazards represent the largest single sector, mitigating factors, particularly Building Regulation and Controls firmly exercised could assist in alleviating other potential hazards as well.

Nevertheless it was interesting to see that with the exception of the London bombing in the financial district, seven of the remaining nine worst catastrophes in financial terms were weather related. Within the United Kingdom overall losses arising in the domestic housing market and taking an average year say - 1977 as compared to 1993 - are currently lower

30 Natural catastrophs and major losses in 1993, Sigma, Swiss Re, Zurich, 1993, table 2, p. 46. 
when allowance for inflation is included, which is indicative of the change in social habits; greater use of central heating, improvements in building methods and construction, and a more accurate assessment of potential hazards when related to "post code areas", etc., etc.

\section{The aims and priorities}

These must be to reduce risks to people and the developed and natural environment by encouraging the provision of technically, environmentally, and economically sound and sustainable defence measures. With regard to the provision and establishement of measures particularly when relating these to structures, we firstly look at Building and Construction Codes of Practice. We must ask ourselves, "What Building Code?" Bests Insurance Management Reports have confirmed that "a factor hard to measure but increasingly viewed as a major culprit in the surprisingly severe damage, is compliance with building codes". ${ }^{31}$ Following the damage caused by Hurricane Andrew, the State Farm Fire \& Casualty Insurance were of the view that up to $25 \%$ of the overall losses could be blamed primarily upon poor compliance with building codes. Other specialists considered the figures could be from $20 \%$ to as high as $40 \%$. Even taking the minimum figure however, we are looking at 1 in every 5 losses being, at the least partially, avoidable.

The Caribbean may be thought of as being possibly a little backward when it comes to building construction methodology, but it was interesting that in Florida after Hurricane Andrew, it was found that what often distinguished "total" from "partial" losses was the presence or otherwise of "hurricane straps". On one housing estate those homes with straps generally withstood the hurricane whilst those with none or unsatisfactory straps were totally destroyed. "Tens of thousands of houses would have generated claims of only $\$ 25,000$ to $\$ 50,000$ had their roofs remained intact. Instead the roofs blew away resulting in average losses of $\$ 150,000 "$ ". ${ }^{32}$ State Farm Fire \& Casualty commissioned a study on homes at the fringe of Hurricane Andrew where winds of $120 \mathrm{mph}$ were recorded. In this study it was found that roofing failures resulting from violations of the Building Codes had occurred in over half the total number of buildings examined.

It is interesting to note that the Farmers Mutual Insurance Co. of the United States sent out specialists to advise clients of preventative methods immediately upon the Hurricane being warned. As a result they state the damage to those premises where they had been able to offer advice was limited to a maximum of $25 \%$ - a result with which they expressed themselves as being "well-satisfied".

When the effects of Cyclone Iniki were reviewed on the island of Kauai it was found that those structures properly engineered in the area heaviest hit by the winds had generally suffered little or no damage. In Fiji the cyclone of 1985 caused serious damage and as a result the practice was introduced of requiring Structural Engineers Reports to confirm the desirability of a structure for windstorm insurance. As a result when a further cyclone of similar severity struck the following year, the insurers losses were 8 times lower $-0.5 \%$ of sums insured when compared to the previous $4 \% .{ }^{33}$

31 Best Insurance Management Reports, Catastrophes, The New Math. Property/Casualty, Supplement, Release 12, May 10, 1993.

32 Dean Flesner, vice-president State Farm Fire \& Casualty.

33 Colin Murray, Catastrophe Reinsurance Crisis in the Caribbean. 
One cannot consider that problems of construction relate only to "under-developed" territories, since the United States has a highly developed regulatory regime; and the effects of the storms of 1987 and 1990 within the United Kingdom showed numerous instances where gable walls collapsed - not being properly tied in - as a result of which the roofs were totally destroyed. Hurricane Andrew also highlighted this form of failure together with an unacceptable performance of building cladding. Again in the United Kingdom we found roofing tiles being stripped where the builders had failed to properly follow the requirements set down by the manufacturers. An example of this was the failure to properly clip and secure the leading edges of concrete-tiled roofs, where the tiles are held secure and rely upon the weight of the upper row of tiles lying upon the lower row. The lowest row being unsecured could be "flipped" back, leaving the next row exposed, et. seq. The United Kingdom has "strictly enforced" codes of Building Practice but in about $50 \%$ of the claims handled by my own organisation we found deficiencies in that regard played a substantial contributory factor in the subsequent damage arising from windstorm.

The most pressing difficulty in mitigation methods however has to be controlling the building replacement programme. In most cases, whilst simple precautions can assist in mitigating the problem to an extent, existing structures are what they are, and whilst some measures may be introduced for strengthening them, it is the replacement structures that are now being erected where we must concentrate on the adherence to proper Building Controls. However, how does the insurance market cater against the Building Inspector who turns a blind eye whilst the contractor proceeds to cut corners, to speed up the work and achieve a higher profit return on his work?

We already have the necessity of receiving an Architects or Engineers Certificate in many cases where it is intended to insure a property against earthquake in a high risk area and the client seeks to convince the insurer that his property is a Class "A" risk. This is a practice which is likely to increase in other areas and against other risks, particularly windstorm and flood as is currently the case in Fiji, the West Indies and other parts of the world.

Politics after a disaster usually means that pressure is brought to bear on insurers to deal with the claims resulting in a more than generous way, and as a result properties underinsured may often be treated - or the insurers are expected to so treat them - as if they were properly and adequately covered. As a result the genuine insured is seen to be subsidising the person who has cut his cover to a minimum on the premise that "it will never happen to him", yet when it does, he expects to be treated as an equal to those who have paid fully for protective cover.

The requirement must be for insurers to insist upon full cover policies being issued up front and to be extremely strict - even to the extent of refusing insurance - for those who undervalue their property.

Hurricane Gilbert gave the writer the opportunity for a post-event appraisal. Despite the severity of Hurricane Gilbert and the financial consequences in the insurance market; and the fact that it is regularly subject to earth tremors lying on and adjacent to fault lines; it is interesting that Jamaica was not even on the list of 10 countries most vulnerable to natural disasters. ${ }^{34}$

34 I.P.C.C. Workshop on Climate Change and Insurance, Amsterdam, March 1994, unpublished. 


\section{The lessons of "Gilbert" - a case study}

Hurricane Gilbert which struck Jamaica on 12th. September 1988 has been mentioned a number of times in passing. I feel it would be useful to look at a specific case study to support my arguments for a closer control of building standards and have chosen Jamaica for this purpose.

Hurricane Gilbert caused damage to the economy, business and private individuals collectively put at the time at some $\$ \mathrm{JA} 7$ Billions (US $\$ 1,268$ millions). Prior to the incident the economy was buoyant with exports up from US $\$ 158$ millions in 1987 to US\$189 millions on an annualised basis, January-September, with inflation running at only $3.5 \% .{ }^{35}$ The result of "Gilbert" was a collapse in the economy, inflation surging, and international borrowings substantially increased which shortly after resulted in devaluation of the Jamaican Dollar, which in turn compounded the liquidity of the nation as international debts were denominated in US\$ and merely increased in line with the rate of develuation. ${ }^{36}$

Hurricane Gilbert was one of the most powerful storms to effect Jamaica with an "eye" 25 kilometres across at the time it struck Jamaica at 1100 hrs., September 12 th, at which time winds were increasing to about $115 \mathrm{mph}$. The hurricane crossed longitudinally along the island of Jamaica and left south of Negril about 0745hrs., 13th September 1988. The majority of the wind recording stations were destroyed but we do know a maximum gust was recorded of $131 \mathrm{mph}$ at Norman Manley International Airport, Kingston, and inland the level of damage to the University of the West Indies at Mona indicated wind speeds, both mean and gust, of a significantly higher level where the winds were funnelled through the Mona Valley. Calculations carried out subsequently show potential wind gust level of up 200 mph at this location.

The hurricane was accompanied by very heavy rainfall, $793.9 \mathrm{~mm}$., (approximately 31.5 inches) being observed at Langley in the northern section of St. Andrew on the south-eastern slopes of the Blue Mountains. This intense rainfall caused rapid flooding of rivers and damaged settlements and buildings along the banks and in low lying areas generally. The rapidity of the water run-off was such that widespread mud slides occurred bringing down debris, rocks and other detritus which also affected the low lying areas and housing and commercial property therein.

Although the intensity of the rain was dramatic the totality of the rainfall was by no means as great as could have been the case because of the relatively fast passage time for the hurricane to traverse the island. In relative terms therefore Hurricane Gilbert was not a "wet" hurricane and in terms of force was only a median incident in terms of the Saffir/Simpson scale. ${ }^{37}$ The total insured losses arising from this incident were approximately

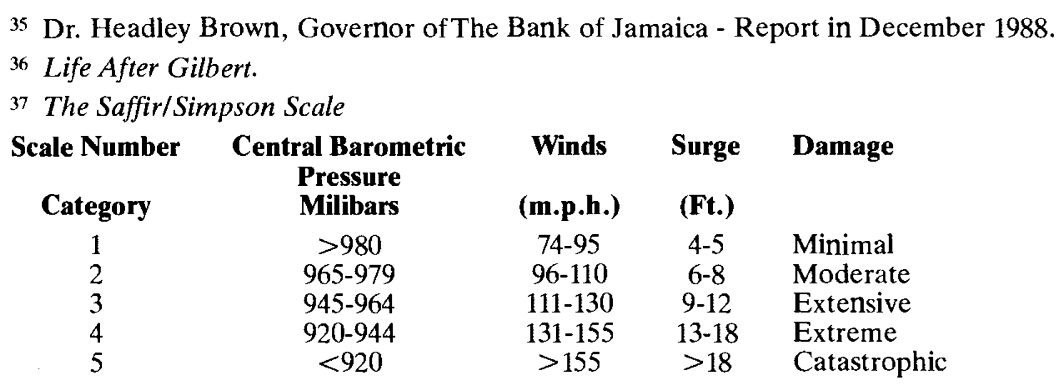


\$JA 4,200 millions (US\$761 millions), with some 70,000 claims notified to the 15 insurers working on the island, this from a country with a population of 2.3 millions and covering an area of 11,525 square kilometres. Fortunately the storm surge on this occasion was relatively modest - approximately $5 \mathrm{ft}$. possibly due to the fact that the depression was still deepening as it passed over the sea until it reached the lowest pressure ever recorded up to that time of $888 \mathrm{mb}$. in the Gulf of Mexico.

So how do we prevent another disaster on this scale? What were the lessons to be learned? Are properties in a hurricane zone insurable? The lessons to be learned may be summarised as follows:

1. Awareness of the probability that a disaster can occur.

2. Short term planning to alleviate the immediate effects and restore normal commercial activity.

3. Long term planning to mitigate the effects.

From an organisational point of view governments have to take the lead. Initially the appropriate persons or authority need to be delegated to ascertain the degree of risk and the likelihood of disaster occurring. Where we are looking at property this envisages the nature and type; and the standards and methods of building construction; together with the identification of those areas where the risk factor is greatest. The government's prime aim has to be the protection of life, but a very close second is to protect the infrastructure and economy of the country. This planning might show the risk to be of an unacceptably high nature, the cost benefits of protection outweighing the value of the potential loss. In such cases construction in these areas might well be prohibited for the future, or a policy of "managed retreat" - particularly in coastal areas prone to flooding - might be employed where the costs of protections outweighs the benefits. However stringent building standards MUST be strictly enforced. We all saw the dramatic benefits of strict Building Regulation requirements that accrued to San Francisco following the 1989 earthquake, and again subsequently in the Los Angeles earthquake - in both cases with relatively low casualties despite the intensity of the tremors.

During the course of Hurricane Gilbert we saw many thousands of properties with sheet aluminium roofs which were patently inadequate and were severely damaged. Whilst the roofing material itself may not have been an unreasonable choice of roofing, the methods by which the roofing was attached to the sub-structure in many cases left much to be desired. In all cases of this type the roofs have to be properly strapped down with the use of hurricane straps to an approved standard. Often the roofing relied for its integrity upon the wall-plate made of timber, which was found to be so eaten away by termites that it offered no cohesive restraint to the forces exerted by the winds. Knowing of the wood-boring insects prevalent in the Caribbean, alternative methods of strapping the roof structures to the walls of the buildings, which latter are generally constructed of reinforced concrete or blockwork - must be considered. Nails driven down through laths and merely bent back to act as "straps", were regularly found; nails which with the vibration and wind pressures, merely straightened and pulled out.

Undoubtedly aluminium roofs and steel sheeted roofs, including those supposedly "hurricane-resistant" were patently not hurricane proof. Wood shingle roofs on the whole suffered considerably less, other than where the entire roof section was lifted up on itself and here again this phenomena occurred mainly in "high quality", modern properties where 
the roofs were not properly anchored down to the structure of the building itself. In the main older buildings - and I speak from experience my family living in Jamaica in a plantation house built in 1740 - were effected only to minor degrees. One has to accept that with the wind force experienced during Hurricane Gilbert some damage was inevitable, but much of the damage that occurred could have been avoided had better construction methods been imposed.

The best form of roofing to prevent damage from hurricanes is the concrete slab roof, most of which showed little or no damage after the passage of "Gilbert". However this form of roofing is the most highly susceptible to major structural damage in the event of earth tremors or quakes - and Jamaica is prone to regular earth tremors. Aluminium and sheet metal roofing, which is relatively light but inflexible is the next most susceptible to damage from hurricanes with anchor bolts and securing bolts tearing through the metal sheeting, while a shingle roof on timber trusses offers a degree of flexibility which also tends to resist moderate earthquake movements.

The lamentable standards of building construction in many ways contributed greatly to the degree of destruction experienced throughout the island. Superficially the homes were modern and of excellent quality, but it was found that on too many occasions shortcuts in building practices had been taken.

Jamaica is probably one of the few locations in the world where a both Grade 5 hurricane and an earthquake of major severity could be experienced. On the basis of this alone a case would be made for a revision of the building standards and in particular - practices. Aluminium sheeting is, unless properly fixed to correctly designed buildings, an inadequate roofing material in hurricane threatened localities. From my personal experiences I would tend to avoid aluminium sheeting in any event, unless it was of a suitably thick grade, as the thinner grades frankly tore apart like sheets of paper. Zinc-coated steel tended to fail when the nails pulled and as a result of there being too few lathes on the roofs. The use of screws rather than nails to secure the sheets would offer greater resistance to pulling and increasing the number of lathes would also have a beneficial effect. The principle failure of wood shingles was similarly due to pulled nails, when too few or too short nails were used. The remedy is to use twisted nails or pull-resistant serrated nails rather than those of straight section and more of them. Zinc sheet tended to fail as a result of broken nails and general rusting, and here the thickness of the zinc coating and regular painting is important - these sheets also should be secured with screw bolts or twisted nails with washers to prevent the heads pulling through the sheet metal.

One also found numerous incidents of zinc sheets, Decramastic and clay tiles failing as a result of twisting in the roofs, particularly where the underlying roof timbers were not laid accurately. This combined with shallow slopes enabled roof damage to occur. At an angle of say $10^{\circ}$ suction can develop and the roof can act very much in the form of an aeroplane wing and attempt to "take off". Steeper roofing slopes mitigate this problem to a large extent.

Clay tiles rely upon regular clipping at intervals along the courses and in particular the securing of the lowermost course and the gable ends. If this was ignored, the tiles could be "peeled" back and expose the property.

Roofing losses were estimated throughout the island at 244,080 units of housing, some 30,235 homes being totally destroyed. The total value of these building losses was more than 
twice the total value of the entire construction costs for buildings erected in 1987. Many of these failures occurred in newer homes which were constructed on the basis of plans which were approved by Local Government Building officers.

Building permits are only issued following submission to and approval by the various Parish Councils of prepared plans. ${ }^{38}$ These plans include details of the roofing system that is proposed. The designers or architects/surveyors are supposed to supervise the construction to ensure adherence to the plans in conjunction with the Government Building inspectors. The system is similar to that practised in the United Kingdom, but as is well known, following the storms of 1987 and 1990 the failures were seen to be just as great in British construction standards as in the West Indies.

The National Building Code of Jamaica was prepared in 1983 and referred to wind loading on roofs. This Code, an extract from that used in the United Kingdom - rccommended a loading factor of $15 \mathrm{lbs}$. per square foot, but a hurricane with winds of $155 \mathrm{mph}$ will exert a force of some $55 \mathrm{lbs}$. per square foot!!! With the aluminium roofing the Jamaican Building code had few specific requirements except to state minimum sheet size. The Building code in use at the time similarly failed to make comment on the lathe size and spacing, nail sizes, screw sizes, types of wood, nail penetration, and other standard wind resistance details that we might take for granted.

Whilst the Jamaican Regulations were based upon British Codes one should hardly need to emphasise that the Codes need to be adequate for the situation in which they are to be used. Design and Construction methods in the United Kingdom differ from those in the West Indies in a number of respects, and indeed the environment also differs to a marked degree, both in the weather conditions and the nature of the potential exposure to disaster.

Whilst high winds are a regular occurrence, the average slope of the roofs in the United Kingdom is substantially greater than in Jamaica with slopes of $30^{\circ} / 45^{\circ}$ being normal, and even steeper slopes often found. These steep slopes reduce the suction pressure on roofs and minimise the risk of damage. Properties in Jamaica are often built with slopes that are almost flat. Whether the roof is constructed of sheet metal or clay tiles, this does result in a hazardous and damage-prone design in the event of high winds being experienced - unless the roof is properly designed and installed.

Aluminium sheeting varied in its thickness or gauge between paper-thin material which was frankly worse than useless which gave occupiers a totally false sense of security to reasonably thick gauge material which - if installed properly - would have been satisfactory. Approximately $80 \%$ of the roofs which failed were constructed with aluminium sheet. These roofs were the only type of roofs which failed due to the weakness of the sheeting material itself. In ALL other cases the failures resulted from the defective fastening of the roofing materials to the rafters or sarking.

Typically aluminium roofs tore completely away from the bolt or nail and left the fasteners intact, even in some cases tearing when held by long $12 \mathrm{~mm}$ bolts topped by wide washers. In other cases the aluminium sheet ripped right across the width of the sheeting. With these and other types of roof covering the manner of fixing to the wall-plate, roofing frame

38 The island is divided into parishes in much the same way as the United Kingdom is divided into Counties, and Continental Europe into Departments, Regions, Provinces and Cantons. 
and wall structures left much to be desired. In those cases where the manufacturers recommendations had been followed both as to gauge and fixing in conjunction with their views on location - damage was limited. Unfortunately however this was only rarely found.

Since aluminium formed by far the largest areas of failure the Jamaican Institute of Engineers suggested that scrupulous attention to proper fixings and anchorages should be given at each of the following points:

1. Sheeting must be adequately nailed or screwed to purlins or laths. Where nails are used they must have special serrations or grooves to increase their "pull-out" resistance.

2. Purlins must be adequately fixed to rafters or joists.

3. Rafters or joists must be adequately fixed to the tops of walls usually by means of wallplates.

4. Wall plates must be adquately bolted to the tops of walls.

5. Vulnerable areas such as gables, edges, eaves, ridges and hips must be provided with an increased number of fixing nails, screws or clips.

6. Roof coverings, laths, purlins, rafters and wall-plates must be inspected regularly to monitor signs of corrosion or decay.

If any of the above fixings is neglected or inadequate the roof will be lifted or stripped off in a hurricane. The only distinction would be whether the roof is stripped sheet by sheet, or whether the entire roof system is lifted "en mass" from the building.

In order to implement these requirements, insurers on their own can chieve only little. Government has to IMPOSE satisfactory building requirements. The problem with any building requirements in any organisation and in any country is that individuals will seek ways to circumvent those requirements - often by the old fashioned means of bribery. In order to avoid this occurring as far as possible it is necessary for individuals and/or government departments to accept full responsibility both practically and financially for adherence to the requirements laid down. One appreciates that with the difficulty of regulating building standards generally problems may be found in implementing this in practice but nevertheless this has to be the AIM. We see how well the results of this have assisted in the reduction of damage and loss of life in the United States with their strict codes of building designed to mitigate against earthquake damage. So it can certainly be achieved.

In 1980, following Hurricane Allen, in Jamaica, I was suggesting the issuing of Certificates in respect of all new buildings and that insurers should refuse to provide cover for windstorm or earthquake unless such a certificate was received by them. This practice is now becoming much more common - both in Fiji and to a lesser extent in the Caribbean. Subject to the system being properly monitored it does at the least partially ensure that at the least, new building work is carried out to an acceptable standard. Existing buildings can also be inspected, particularly where they are prestige or high-occupancy structures. With older buildings steps can be taken to strengthen them against the risk of damage - particularly with regard to the condition and the fixings of roofing.

I have already commented upon the shallow angle of roofing in the Caribbean and the problems this can cause. This will create a substantial "suction" effect on the slope of the roof facing away from the direction of the wind, rather in the form of the "lift" created by the wing of an aircraft. Such suction causes "rippling" to occur, particularly in those sheet metalled roofs. The intense low pressure passing over as the hurricane crosses will often 
result in the air pressure within the building being higher than the atmospheric pressure outside with the tendency for the roof to "explode" outwards. This can be counteracted by opening the windows on the sheltered side of the property away from the direction of the wind, and as the "eye" passes over, closing those windows and opening the windows on the opposite side of the building, which is now sheltered. The shallow angle to which the roofs are normally constructed however, enables the wind to get beneath the eaves, and when combined with the pressure build-up within the property, if the roof is not properly strapped, can cause the roof to lift off. Once the edge of the roof has risen approximately $10^{\circ}$ the wind force will be sufficient to lift this in its entirety and flip the complete section over.

It was particularly interesting in Jamaica to see that in those instances where the buildings were constructed with a small mini-parapet with the sheeted roof behind that parapet falling into an internal gutter, the amount of damage even to inadequately secured aluminium sheets was minimal. Generally only the ridge pieces and some side gable sheets would be damaged or removed. So one lesson to be learned is that designing a building with a low parapet at the bottom of the slopes where metal sheeted roofs are concerned will certainly mitigate the level of potential hurricane damage.

Approximately $70 \%$ of the structural damage claims arising from Hurricane Gilbert were contributed to by poor standards and poor quality in building methods and construction, and perhaps a further $15 \% / 20 \%$ by faulty design. Some $85 \% / 90 \%$ of all losses could therefore have been reduced!!

This level of "failure" had an effect on contents claims and consequential loss of business. With a roof gone and some 30 inches of rain falling - the contents did not stand a chance. Similarly the use of proper storm shutters is to be recommended as with the winds experienced, rainwater was driven horizontally through the louvered windows of many structures - particularly commercial - resulting in severe damage to contents even when the roofs were unaffected - as in slab concrete roof construction.

Jamaica requires approximately 6,000 new housing units each year to replenish wornout stock, representing about $1 \%$ of the total potentially insurable housing stock, ${ }^{39}$ and if only those properties were forced to construct to the required standards, over a relatively short period of time, when combined with upgrading of existing properties where possible - the overall improvement of the potential risk to insurers would be substantial. When hurricanes occur there follow chronic shortages of suitable materials, at least in the short term. One obviously cannot stock-pile roofing sheets for an emergency - and it is clearly better to have the properties properly constructed in the first place to avoid the necessity for replacing and repairing what turned out to be some $70 \%$ of the roofs of all insurable private properties on the island.

Professor Nicholas Ambraseys, professor of Engineering Seismology at Imperial College, London, has pointed out in countries such as Greece, Turkey and Italy, small houses in rural areas are frequently built under the supervision of the owner "who tries to cut corners in order to cut costs, and who is entirely unaware of what nature has in store for him". This practice is certainly not confined to those countries, as both in Jamaica - and dare one say it, in the United Kingdom - short cuts account for much of the problems eventually

39 Much of the housing stock is low value corrugated iron "shanties" occupied by the poorer individuals which would not be insurable in any event. It is interesting to note however that these very "temporary" buildings were the first to be repaired - generally with metal sheets "acquired" elsewhere! 
experienced when nature intervenes. The use of Certificates confirming standards being complied with as a requirement for insurance would assist in combating this problem but only in those cases where the economy of the area permits the owner to actually afford the premium for the insurance in the first place. Lastly the problems of low-wage economies can lead to difficulties with regulation where pay-backs and bribes may be more common than the authorities would care to admit. Those persons responsible for the issuing of certificates must therefore be both responsible and capable of being held responsible for deficiencies in the system.

\section{Conclusion}

Maintenance of the requirements has to be a key element in the provision of defence mechanisms. Poor maintenance of the systems, whether these be flood defence or regulatory requirements, will increase the risks of failure and reduce its effectiveness in combating financial loss to society.

The Insurance industry can NOT sit back and do nothing. Dr. Gerhard Berz, Chief Scientist of the Munich Re. when speaking to the International Allianz Forum earlier in 1994 stated that if insurers do not take account of climatic changes the "future of the whole insurance industry could be at risk".

Global insurers do need an International forum where they can influence, cooperate and sponsor actively new inter-disciplinary initiatives to tackle the key risk areas of flood, windstorm and earthquake. Earthquake initiatives, particularly in the well developed economies of Japan and the United States are already well advanced and have been to be extremely effective in reducing the loss of life from these events, and to a lesser extent mitigating the financial property loss also. Even then natural disaster can be cataclysmic as was seen recently during the Kobe earthquake. However this needs to be extended to those areas of the world less developed where loss of life from comparatively minor tremors is still at unacceptable levels. In such areas however, insurance against financial loss is at a relatively low level and insurers would therefore have less of a direct interest or, more importantly, influence in the potential property losses in such locations due to their lesser exposure. The most serious exposure world-wide however is flood with its huge loss potential, and even in less developed countries, whilst domestic housing might be a low priority for insurance protection, the means of providing power for production, distribution and manufactures are often in areas of high risk. Insurers should insist on becoming involved in planning, design, construction, protection and funding to a greater degree than is currently the case, and with their wealth of experience could play an active and useful rôle assisting other countries to develop such protective risk limitation methods, particularly in the areas of windstorm and flood.

The development of products specifically tailored to the particular areas should be proactive, rather than re-active as at present. Whilst it is easy to merely increase premiums or withdraw from a market, it would be of greater benefit to the society locally if products could be arranged using perhaps co-insurance, first-loss policies etc., which whilst ensuring a continuity of policy cover against the eventuality, and maintaining some cover for the consumer would at the same time potentially limit the insurers exposure. It may be suggested that this is just what has been done currently in Jamaica for example against hurricane loss, but the way it was structured by the re-insurers has resulted in there being an active 
disincentive to insure at all for any risks - which is probably not quite what the insurers were seeking to achieve. By effectively denying cover for the risks, insurance is failing fundamentally to provide the service required.

Commercial organisations could be induced to participate in protective measures not only to avoid damage to their earning capability, but also to reduce insurance costs and, possibly as a result of pressure put upon them by financial institutions and banks who may see their collateral security being less attractive if not properly protected and insured.

All of this depends upon good information technology to ensure the risk appraisal is undertaken as accurately as possible and is based upon the latest known information as to environmental patterns; and to this end all government institutions and research establishments need to cooperate with those research establishments of our industry to ensure interaction of information on a global basis.

Insurers should insist upon the development of enforceable recommendations for building construction regulations, an area where cooperation with the United Nations sponsored IDNDR should be encouraged. This should also encompass land utilisation and protection against inundation from river, estuarine and coastal flooding. Warning measures of impending incidents have been shown to be able to effectively reduce the level of financial loss when put into practice, and this also should be encouraged.

Insurers must not be negative in their reactions - withdraw from the market or increase premiums to unsustainable levels - but should encourage the overall improvement in the risk by rewarding those who have effected higher building standards with sensible premiums - possibly on a co-insured basis with the insured.

The Munich Re have calculated that if a blanket US $\$ 1,000$ deductible were applied to losses, this would reduce the overall number of claims by approximately $50 \%$ with a consequent saving not only in claims costs, but in the costs of administration also. Cover should be obtainable for what to the individual is a personal catastrophe - not merely the accidents and losses of normal life, but cover for the substantial loss should be available and affordable. However one might suggest that the actual level of deductible needs to be tailored to the specific market. US $\$ 1,000$ may be correct in the United States, UK, France and Germany, representing perhaps $1 / 35$ th. of average income, but in other less developed countries such a level of deductible could represent the equivalent of $1 / 4$ of the annual income or more, and as such be unacceptably high - given that the latter case could be an insurable person in the first place. By merely refusing cover in a location insurers do not encourage better building construction methods - but encourage reversion into gretaer decay and dilapidation and ultimately encourage governmental interference in their financial marketplace.

Governments where insurance cover is not readily available may initially be encouraged to merely sit back in the anticipation of overseas aid but, with the escalation in the requests for such assistance, whether this be the result of climate disasters such as hurricane or environmental problems arising from drought, no government can really be complacent in the thought that such offers of international assistance and help will always be available. As the resources of individuals and individual countries are limited, governments should be encouraged to be as self-sufficient as possible, and primarily this includes being properly and adequately protected by insurance in all its forms. The coastal and estuarine defence measures undertaken by the Ministry of Agriculture, Fisheries and Flood in conjunction 
with the National Rivers Authority in the United Kingdom is an example of such "insurance". Provided this is accompanied by adequate building control regulations, properly enforced, the risk of actual loss would be that much less.

In many cases the financial institutions - and here we refer to insurers - have to pay for the omissions of society as a whole. Should these insurers therefore influence government policy? Even in disaster situations, governments do not overlook the real benefit that accrues, as in the case of Jamaica, from the inflow of hard currency from insurers and reinsurers worldwide; albeit this hard currency was used to alleviate damage and distress. In the case of Jamaica the costs of remedial work were paid almost exclusively in Jamaican dollars, whilst funds from insurers were remitted in UK Sterling, USA Dollars and German Marks. The labour content of the remedial work was paid exclusively in Jamaican dollars. Whilst the cost of imports, particularly building materials and foodstuffs rose substantially the hard currency of approximately US\$650 millions from the insurers and the re-insurers was available to pay for these goods.

In addition to the monies received from the insurance market Jamaica received a total of US\$583.15 millions, equivalent to JA $\$ 3,219.6$ millions for reconstruction of the economy in the form of overseas aid from various foreign governments and financial agencies. Of this amount JA $\$ 787.19$ millions was in the form of "grants". However the balance of JA $\$ 2,432.41$ millions was in the form of loans, which by their very nature are repayable. 40 Such loans serve only to increase foreign indebtedness and ultimately have to be funded by the efforts of the entire community. This in turn will lead to higher taxation, duties, etc., in the absence of sharply increasing commercial productivity. By the very nature of disaster on a wide scale the community is hardly in a position to manage this immediate increase in commercial economic performance until restoration is complete, and we therefore have something of a "chicken and egg" situation - a commercial viscious circle. Even with all the loans, grants and insurance recoveries there was still a shortfall of at least US\$65 millions when related to the overall tangible loss incurred by Jamaica - to say nothing of the intangible losses - reduction in tourism etc., that resulted from this incident.

From the above it can be seen that anything that can be done to mitigate the potential losses from disasters such as hurricanes, floods or earthquakes, can only be seen as a good investment for the future well-being of a nation, despite the fact that, in the short term, the cost of providing such "insurance" may appear unnecessary. It is interesting to note that shortly after the hurricane's effects had been appreciated the Jamaican dollar was devalued from JA $\$ 5.52 /$ US\$ to an official rate of JA\$6.50/US\$. The effect of this was to immediately increase the amount of loans requiring repayment from JA $\$ 2,432.41$ millions to JA $\$ 2,864.25$ millions; 41 an increase of some JA $\$ 431.84$ millions, without taking into account the interest liability being incurred in addition. Subsequently further devaluations have only compounded the problem. Currently the exchange rate is in the order of JA \$42/US\$. Whilst it is not suggested that each devaluation was brought about solely by Hurricane Gilbert, there can be no doubt but that this provided a very severe "jolt" to the nation which at the time was on an economic crest.

Clearly therefore there must be every encouragement for government to work in cooperation with insurers in mitigating the potential effects of environmental disasters and

40) Dr. Headley Brown, Governor of the Bank of Jamaica.

41 Dr. Headley Brown, Governor of the Bank of Jamaica. 
achieving insurability. The Building Codes, now enacted in Jamaica and in Fiji as examples, have materially assisted in this regard, but insurers may well still be too timid to take proper advantage of this - possibly not unsurprising given their past experience - but one says again - the insurance industry must become pro-active on a global basis.

For the insurance sector to be able to deal with RISK CONTROL it is therefore a requirement that cooperation and dialogue with governments ensue to examine a country's infrastructure and methods of disaster preparedness. This cannot be achieved by one insurer on its own but should be the responsibility of the market as a whole. Whilst this may have been possible with a large insurer or group of insurers in their own territory with the increasing international nature of insurance it now requires international representation and on a global basis. One poses the question - Could not the Geneva Association (which being based in Switzerland is already perceived as being impartial) be the progenitor of this approach for full international recognition of the problem on a market led basis? This is what is meant by being pro-active, which sadly the insurance industry is NOT in this area.

Effectively by their interest in a country's infrastructure, insurers would be helping to "control" and influence their own investment interest, and indeed that of their own customers, in mitigating the potential levels of financial loss to society. Effectively one is looking at Risk Survey - but on a grand scale. I was privileged to gain an insight into "Jamaica Inc." and looking at the problem from the Government's point of view it is clear that insurers are not necessarily providing all of what is required, often as a result of international lethargy in considering risk control in participation with government and in endeavouring to minimise their own risk exposure.

The whole philosophy of insurance needs to be considered with regard to potential interference from government which, without that cooperation, could and in some instances does, make life difficult for the insurer. We have already seen rigid price controls of premiums - as in Israel which resulted in insurers going into liquidation or in California where companies are not allowed to increase premiums following the recent earthquakes; requirements to provide cover however bad the moral and/or physical risk - California again; compulsory insurance; government regulation and direction of investments and assets; insurers being prohibited from voiding claims even where information is false and possibly fraudulent; restrictions on profits, etc., etc., the list is endless.

At the end of the day we start where we began, in that Government is the insurer of last resort, if only as the organiser of the Disaster Relief Fund! And on this basis the central governments, possibly through the auspices of the United Nations, are needed to give that authoritative leadership both as to research, prevention where this might be possible, protections where this is not, and to cooperate with thosc private commercial institutions who are prepared to carry the financial risks associated with disasters. In its way Insurance is one of the methods of mitigating the effects of disaster and can be looked upon as a form of disaster preparedness. ${ }^{42}$ This co-operation through Government extends not only to the physical and research regime, but to the very essence of public responsibility - that of providing an incentive by taxation not only to individuals but to those financial institutions prepared to carry the risks for Society - an emotive subject, which is another paper in itself!

42 Gerhard Berz, The Insurance Industry: Common interests and tasks, Stop Disasters, United Nations IDNDR Newsletter, Sept/October 1993, p. 8/9. 


\section{Acknowledgements}

In addition to those sources shown in the footnotes I would like to thank the help provided initially in my research by Dr. J. Edward Greene of ISER, The University of the West Indies, Mona, Kingston, Jamaica, who originally suggested the idea of the research into Hurricane Gilbert, and Neville Henry of the N.E.M. Insurance Co. (Jamaica) Ltd., together with my own colleagues in Toplis \& Harding.

Working with Andrew Dlugolecki of the General Accident, Perth, on a project for The Society of Fellows, one found a person of similar interest and tremendous enthusiasm for a subject often dismissed by insurers seeking an easy way out. The co-authors of The Impact of Changing Weather Patterns on Property Insurance with Andrew and myself were Caroline Elvey, Jeremy Hindle, Geoffrey Kirby, Jean Palutikof, Ronald Salthouse, Charles Toomer, Steve Turner and David Witt. Subsequently Roy Hathaway of the Ministry of Agriculture Fisheries and Flood gave a different insight into the problems of planning for which I am extremely grateful.

Lastly I owe a debt of gratitude to Cyril Dakin, the master who some 36 years ago first nurtured my interest in economics and the real world. 